\title{
SPECIAL ISSUE DEDICATED TO THE TWELFTH "JOURNÉES MONTOISES D'INFORMATIQUE THÉORIQUE" FOREWORD
}

This special issue of RAIRO - Theoretical Informatics and Applications is dedicated to the twelfth conference "Journées Montoises d'Informatique Théorique" (Mons Theoretical Computer Science Days) which was held at the University of Mons in Belgium from 27th to 30th August 2008.

The conference was back to its place of birth ten years after the last edition in Mons. Previous editions of this conference took place in Mons 1990, 1992, 1994, 1998, in Rouen 1991, in Bordeaux 1993, Marseille 1995, Marne-La-Vallée 2000, Montpellier 2002, Liège 2004 and Rennes 2006.

Around 65 participants from Belgium, Canada, Czech Republic, Finland, France, Germany, Israel, Italy, Russia and UK were attending the meeting and discussing about the main topics of the conference: combinatorics on words, automata theory and formal languages theory and their relationship with other topics like number theory, model-checking, logical aspects, theory of semigroups, game theory, algorithmic aspects, etc.

After the conference, participants were invited to submit full research papers for this special issue. Each paper has been refereed using high scientific standards by two independent referees.

We would like to thanks the invited speakers: Boris Adamczewski, Vincent Blondel, Gregory Kucherov, Dominique Perrin, Gwénaël Richomme, Igor Walukiewicz but also all the participants and the anonymous referees who made possible this event and special issue. But also we do not forget our main sponsors: European Science Foundation (through the AutoMathA program), FNRS (Belgian Science Funds for Research), the University of Mons-Hainaut and l'Académie Universitaire Wallonie-Bruxelles.

Véronique Bruyère and Michel Rigo, Mons, 15th October 2009. 